\title{
Strategic study of total innovation management and its relationship with marketing capabilities in palm conversion and complementary industries
}

\author{
Neda Baniasadi ${ }^{1,4^{*}}$ D, Davoud Samari ${ }^{2}$, Seyyed Jamal Farajollah Hosseini $i^{3,4}$ and Maryam Omidi Najafabadi 3,4
}

\author{
*Correspondence: \\ Nedabaniasadi@ymail.com \\ ${ }^{4}$ Present Address: \\ Department of Economics, \\ Agricultural Extension \\ and Education, Science \\ and Research Branch, Islamic \\ Azad University, Tehran, Iran \\ Full list of author information \\ is available at the end of the \\ article
}

\begin{abstract}
Given the role and importance of processing and complementary industries in preventing waste from agricultural products, the establishment of such industries can be considered as one of the most appropriate solutions for agricultural development. For this purpose, the data were collected for data processing and complementary industries in the fields of packing, pricing, customer orientation, in south of Iran. Method: According to the goals and assumptions, descriptive-analytical research and its survey method is a survey. According to the Cochran formula, 155 people are involved in marketing, packaging and processing of palm in Kerman province. To answer the research questions, SPSS software and AMOS software were used to analyze the results. Findings "Indigenous Knowledge in packing". Using communication tools in marketing impact of customer-orientation approach are Top Priorities in "marketing Date". The "packaging" factor is the most important factor in the marketing development of date conversion and complementary industries.
\end{abstract}

Keywords: Total innovation management, Conversion and complementary industries, Date, Marketing, Agri-food system

\section{Introduction}

The agri-food system (also called food system) is "the way in which people organize themselves, in space and in time, to obtain and consume their food". According to FAO (HLPE, 2014), a food system gathers all the elements (environment, people, inputs, processes, infrastructures, institutions, etc.) Today, all the components of the agri-food systems are concerned by a huge need for innovation to reach sustainability (Tilman \& Clark, 2015).

Agro-industry is an activity that uses the product of the primary sector (agriculture, plantation and forestry) as raw materials, designing and providing the equipment and services for the primary sector itself (Adriadi Ghiffari, 2016).

Given that the food industry in the industrial world is accompanied by intense competition and the active presence of large transnational companies, competition author(s) and the source, provide a link to the Creative Commons licence, and indicate if changes were made. The images or other third party material in this article are included in the article's Creative Commons licence, unless indicated otherwise in a credit line to the material. If material is not included in the article's Creative Commons licence and your intended use is not permitted by statutory regulation or exceeds the permitted use, you will need to obtain permission directly from the copyright holder. To view a copy of this licence, visit http:// creativecommons.org/licenses/by/4.0/. 
in this industry goes beyond national borders and puts a lot of competitive pressure on activists in this field. The food industry in Iran is one of the important and influential industries in the economy, which will undoubtedly face many changes with the globalization of the economy and increasing competitiveness. In such a situation, to maintain the position and to create the value-added for customers and maintain them, food companies are forced to create competitive advantages for themselves and they try to maintain and develop these advantages (Food Industry Strategy Plan, 2016).

The activity of the conversion and complementary industries causes value-added of the product, job creation, prevention of waste, improvement of export situation, encouragement and encouragement of producers and direct impact on the economy of horticultural production areas of the country, has a special place and importance. Agricultural development is not only limited to increasing yields, but also includes diversification and processing, waste reduction and value-added production. Therefore, it is necessary for the agricultural sector to prepare beyond its livelihood functions for new roles (Mcleod Rivera \& Kalim Qamar, 2003).

Complementary industries refer to a set of industries that by performing physical and chemical changes on raw materials of plant and animal origin in terms of processing and processing, grading, packaging, storage and marketing and distribution of the resulting products. Conversion and complementary industries agricultural is transformed into another form for better consumption, better supply, and increase of economic value in such a way that the nature of the new product is the same as the nature of the raw material, but the final product of a new material is the same as the raw material (Qami et al., 2011).

Establishment of conversion and complementary industries has positive and significant effects on strengthening the rural economy, increasing the level and variety of products, as well as preserving agricultural lands and rural landscape. Given the natural and social characteristics and talents of the region and the positive effects of agriculturalrelated industries, linking the two sectors of agriculture and industry is mandatory to achieve sustainable rural development (Poorramezan \& Akbari, 2014).

Dates are considered as one of the strategic products among the agricultural products for Iran and one of the most important garden products in this country. Iran has around $17 \%$ of the cultivated area and 13\% of the world's date production (Statistics of the Ministry of Agriculture, 2017).

Date fruit is an important commercial crop in the Middle East. According to the Food and Agriculture Organization (FAO), in 2013, the area under date cultivation in the world was 1,112,490 ha and world production was 627,624 tons. Meanwhile, Iran's share is estimated 162,998 tons from cultivated area 1,083,720 ha. However, a large amount of dates in different stages of production turns into waste for many reasons. For instance, due to the high waste of dates in Iran and the lack of sufficient conversion and complementary industries, a significant amount of these valuable products is destroyed annually (Behbahani, 2017).

Recently, Food Loss and Waste (FLW) has been the subject of much discussion. When it comes to food security, potential economic benefits, natural resource conservation, scientists, politicians, and the general public, agree that FLW needs to be reduced. 
However, the way the FLW problem is presented and analyzed faces numerous inconsistencies (Chaboud \& Daviron, 2017).

The privatization of the public infrastructure for agricultural knowledge was the most important change in the Agricultural Innovation System. Agricultural knowledge and information were regarded as public goods offered by the state through extension services and publicly applied agricultural research institutes (Lacy, 2001).

The privatization of public knowledge infrastructures in agriculture was the second major change in the Agricultural Innovation System Agricultural knowledge and information were viewed as public goods provided by the state through advisory services and publicly applied agricultural research institutes (Lacy, 2001; Rivera, 2000). In practice, however, these were often not the exclusive source of knowledge and information for innovations as private service providers were also active. Privatization has resulted in either the acceleration or emergence of a market for agricultural R\&D and KIBS for the US, depending on the local context, for the support of agricultural innovation (Leeuwis \& Ban, 2004; Levidow et al., 2002).

Information and knowledge become private or chargeable goods. From the perspective of an innovation system with a strong emphasis on effective linkages between actors, the changes discussed above at the interface between producers and users of knowledge and information present a number of limitations and challenges for actors in agricultural knowledge infrastructure. In order to meet these new demands, state farmers are encouraged to be more market-oriented, to look for new opportunities and to act more strategically. This shift from production to business and market orientation has drawn attention to the appropriateness and application of general business skills in the agricultural sector compared to technical skills and knowledge in animal and plant production (Klerkx \& Leeuwis, 2008).

Marketing: It is a technical economic practice that minimizes the cost of goods development while increasing sales and thereby maximizing profits (Afrasyaby, 2010).

High demand for the high quality of fresh food has pushed farmers' interest in marketing, creating social connections and vibrant shopping experiences, and widespread health issues, and has always pushed farmers toward marketing (Hamilton, 2005). Branding: price, along with "location (or distribution) and promotional activities", is one of the four pillars of marketing. Proper pricing, along with its components in the success or failure of a business, has a significant impact on income through the mix of marketing pricing as a major parameter (Dolgui \& Proth, 2010). Marketing relations include various components such as sales promotion, public relations, direct marketing and advertising, which is an important part of marketing. Marketers use advertising to raise brand awareness, build branding between other brands, and ultimately the name of commercial brand by the customer (Abbasi \& Mohammadian, 2007).

The brand name is an important driver of new product success. However, if consumers perceive inconsistency between the existing name and a new product, they may react unfavorably toward the new product, as well as the brand and its existing product (Truong et al., 2017).

Shafei and Naziripour (2013) considered pricing as a behavior, culture, information flow, decision making, and strategic planning and as the least costly way to address customer problems and customer management. Since the date industries of Kerman 
province has not been able to reach the world markets in the field of marketing, packing and processed products, this paper examines the development of date processing and complementary industries with an emphasis on comprehensive innovation management.

In Iran, most of the dates produced in conversion industries, are consumed as date juice, cake, cookies, etc. In addition to job creation, the exports of these types of products can be increased by investing in conversion industries.

Dates in Kerman province are sold in bulk and nonstandard packing to brokers and due to the lack of skilled manpower and innovation in processing and complementary industries of date. This product could not have a significant share in global markets. Also, the participatory method and use of indigenous knowledge are very insignificant in the institutional and organizational field.

The agro-processing industry, with creating food security, has an important role in improving poor people's access to food and increasing their purchasing power. According to proper marketing and transportation, processing industries can have an important role in rural development.

The agricultural products marketing in Iran has not made much progress. Therefore, the marketing of these products should be out of its traditional mode and turn into an advanced mode. This issue highlights the importance and necessity of innovation in the marketing of agricultural products. In the current situation, traditional marketing methods have lost their effectiveness because of the increasing consumer awareness of agricultural products. Besides, the need for innovation in conversion and complementary industries is more important than ever in business and agricultural production activities.

\section{Literature review}

\section{Framework and overview of modeling approaches}

Conversion industries guarantee food security and play a vital role in improving the accessibility of poor people to food and improving their purchasing power. Cost-effective conversion and complementary industries, with proper marketing and transportation, play an important role in rural development (Olamade, 2014).

The establishment of industries increases the interest in agricultural activities. Eventually, in the environmental dimension, reducing the waste of agricultural products, healthier supply of food products, and considering codified programs to observe the health of the rural environment have been the most critical consequences of establishing conversion and complementary industries in the agricultural sector. Transformation industries in the agricultural sector can be expected that a high percentage of agricultural products produced due to incomplete marketing and low selling prices in agricultural lands, can be purchased and used in these industries at a reasonable price and easily (Karami et al., 2019).

\section{Total innovation management}

Total Innovation Management (TIM) discusses the components of strategy, culture, organization, and the relationship between them (Xu et al., 2007). It presents a model for the relationship between technology and non-technology. This new model integrates various characteristics of innovation and traditional innovation. The main emphasis of traditional innovation management has been the creation of technology or innovation 
processes, and the role of management includes processing inventions or innovating the product (Zhirong et al., 2003).

Performance in traditional innovation is related to R\&D. A key factor in traditional innovation is competitive advantage. Also, in total innovation management, the function of cultural elements, organizations, innovators, place and time are important (Xu et al., 2007).

Important components of Total innovation management are Innovation strategy, Innovation culture, the organizational structure, technology management, and innovators. In this respect, innovation synergy is among the innovative elements.

The notable difference between total innovation and traditional innovation management is that it breaks through the previous innovation framework, which is only limited in the research and development department. The employment of TIM goes through three transformations ranging from individual innovation to overall innovation, from separate innovation to integrated innovation, and from a focus only on the company's internal resources to an emphasis on the integration of internal and external resources.

Innovation is therefore not only the responsibility of a few people or functions, but also in an integrated strategic process for value creation and creation. TIM demands that all functions and all employees are involved in the overall innovation-the resources for innovation will be much higher and the costs of applying TIM will grow consequently. If TIM is not linked to the innovation strategy to create more value in the market than it costs, TIM is therefore not supported and subsequently not carried out.

In a dynamic and complex market, only continuous innovation can drive a company's sustainable growth and profits. In the innovation process, however, companies often get caught up in the "war of innovative wear and tear" (Braun, 1997) and lead to what is known as the innovator's dilemma (Christensen, 1997). Much research and practice has shown that innovation must be brought into the framework of corporate strategy in order to overcome this dilemma and serve the process of changing business strategy (Janszen, 2000; Xu et al., 2007).

The implementation of TIM undergoes three transformations. They range from individual innovation to total innovation, from separate innovation to integrated innovation, and from a focus only on the company's internal resources to a focus on the incorporation of internal and external resources. Innovation is therefore not only the responsibility of a few people or functions, but also in an integrated strategic process for value creation. TIM should be integrated into corporate innovation strategy such as R\&D (Roussel et al., 1991).

Strategy implementation should be supported by organizational and institutional innovations (Janszen, 2000). According to institutional economics, the establishment of an institutional innovation entails two prerequisites: on the one hand, the innovation changes the latent profits and, on the other hand, the innovation costs must be lower than the added profits (Davis \& North, 1970).

TIM demands that all functions and all employees to take part in total innovationthe resources for innovation will be much higher and the costs of implementing TIM will increase consequently. If TIM is not linked to the innovation strategy to create more value in the market than it costs, TIM is therefore not supported and subsequently not carried out. 


\section{Innovation dimensions}

First, product and/or service innovation implies changes in a product or service provided by the organization by using new or existing technologies. It refers to the development and marketing of new products and services, related to customer satisfaction. Second, process innovation, which includes changes in the way in which new or significantly improved products or services are created and delivered. It is the development of different ways of manufacturing and providing services. Third, marketing innovation (competitive position), which refers to changes in the context in which goods or services are introduced to the market by focusing on the consumers' needs. It is the development of new power and leadership structures. Lastly, organizational innovation (management or mental process), which comprised changes in the underlying mental models which shape what the organization does, therefore, it is the result of strategic decisions taken by the company through a newly developed business in order to provide a sustainable competitive advantage (Ganzer et al., 2018).

\section{Marketing innovation}

Marketing innovation addresses the implementation of new methods, with significant changes in product development, packaging, promotion, positioning, and even in pricing. Therefore, marketing innovation seeks to address the consumers 'needs, by the way new markets are opening, the product repositioning of a company within the market, aiming to increase sales (OECD, 2005).

Development indicators of a local foods supply were positively related to the choice to engage in marketing. Factors affecting farm financial performance varied significantly between a short-term and a long-term measure. The results emphasize the importance of considering multiple outcome measures, developing local supply chains and provide implications about beginning farms (Clare Ahearn, et al., 2018).

Ali Abadi et al. (2009), in a study entitled "Smart Packing in the Food Industry", factors for smart packaging such as temperature and time indicators, gas concentration controller, increased ease in the production and distribution of anti-counterfeiting and theft systems and increase the safety and quality of food products.

Eskandarpour et al. (2014) carried out a study entitled "The Uniform Price Law and Integration in Global Date Markets". The results of the study indicated that the convergence of prices in global markets and among major exporters such as Iran, Tunisia, Emirate, Iraq and Saudi Arabia could make it possible to access markets. It should be noted that there is price convergence and the unit price law in the long run between global prices and export prices in Iran's export markets.

Tsai et al. (2017), in an article entitled "Experiential value in branding food tourism", achieved the results that branding could significantly increase the return on investment. Illustration in branding, such as local food image has a significant relationship with an increase in tourism.

Rapp et al. (2010) postulates that customer-orientation is the collection, sharing, and use of information with customers at the organization level and coordinated actions based on this information. Customer orientation, as a dimension of market orientation, emphasizes the importance of identifying and addressing the needs and preferences of buyers and customers (regardless of other dimensions of market orientation). 
Market innovation is orientation. Market innovation means the innovation of marketing channel, the operational ways et al., by which to create new market, new channel and new ways. Innovation synergy is approach. Due to the inherent limitation of isolated innovation, it is necessary to integrate all the innovative elements systemically. Synergy of all the innovation agents has becoming the dominant paradigm of innovation management both native and abroad since 1980s, and it is the basic approach to realize TIM (Zhirong et al., 2003).

Previous studies on the marketing process in the field of agriculture considered effective factors such as the role of marketing, the role of consumers, the role of product design and startups on this process but in various fields, however, this study seeks to find research weaknesses in this field so that it has been conducted with the aim of studying the TIM in the marketing process of date processing industries.

Although processing industry is not the only solution to increase the rate of employment and the incomes of rural people, it is definitely the best and most productive way, as many economists and politicians consider the employment as a way to prevent migration of villagers, besides, rural chaos. Employment can improve the income of villagers, especially rural women, who can work near the residence to become self-sufficient and reduce their needs (Imani Jajrami, 2009).

\section{Modeling approaches}

\section{Materials and methods}

TIM includes components such as innovation culture, innovators, innovation strategy, organizational structure and technology management (Omani \& Salmanzadeh, 2015). The findings also showed that marketing of processing industries consists of components such as packaging, marketing and processing diversity (Dey et al., 2018).

Omani et al. (2015) found that innovation can improve the processing industries, moreover. In this section, the conceptual model of research is drawn according to the previous sections of the study and in the form of the central research hypothesis (i.e., comprehensive innovation management on the marketing of conversion and complementary industries of dates) and based on the review of theoretical texts and related empirical studies. As shown in Fig. 1, comprehensive innovation management consists of five components (namely, innovation culture, organizational structure, technology management, strategic innovation, and innovators). These components affect the marketing of date conversion and complementary industries, including three parts (customer orientation, packaging, and pricing). According to these points, the hypothesis of this research is as follows.

What are the components of comprehensive innovation management in the marketing of date conversion and complementary industries? Is there a significant positive relationship between the elements of comprehensive innovation management and marketing of date conversion and complementary industries?

This research is applied in terms of purpose, quantitative in terms of data collection method, and survey in terms of implementation method. The present study consists of two phases: (1) reviewing theoretical and experimental foundations and (2) field study. In the first phase, the theoretical and experimental foundations related to the research subject area were studied. Based on the purpose of the research and literature review, 


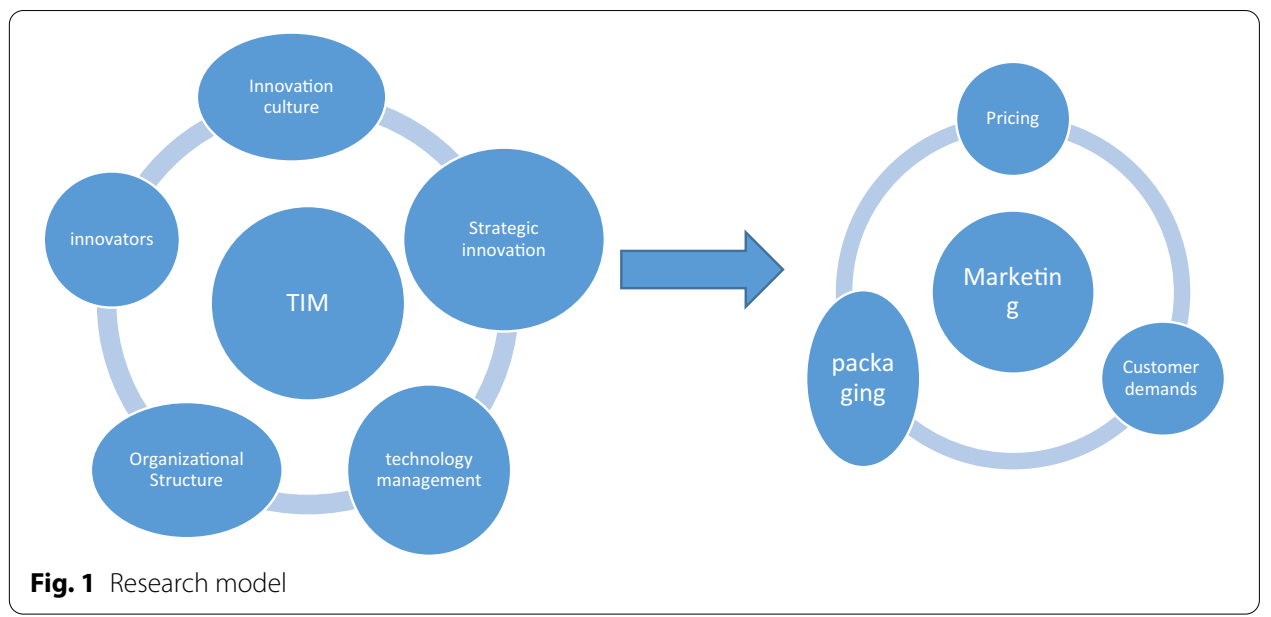

research backgrounds, and hypotheses, the conceptual model of the research is presented in Fig. 1. In the second phase, the indicators for measuring comprehensive innovation management in date conversion and complementary industries were designed using a quantitative approach and field study.

The statistical population of this research includes 200 persons who work in the field of marketing, packaging and processing of date products in the processing industries in Kerman province. The sample size was determined to 155 persons by Cochran formula and simple sampling method. The data were collected through researcher-made questionnaire which has 58 items according to Table 2; moreover, it has been scored by 5 -point Likert scale (completely agree $=5$, agree $=4$, no opinion $=3$, disagree $=2$, and completely disagree $=1$ ). The viewpoints of experts and Cronbach's alpha were used, respectively, to determine the validity and reliability of the questionnaire, finally, the obtained values were higher than 0.70 so that reliability was also confirmed.

In this research, to analyze the data and hypotheses of the study, descriptive statistics (e.g., mean, median, and variance) and inferential statistics (structural equations) are used. In addition, structural equation model (SEM) is used to confirm or not confirm using AMOS structural equation software and SPSS software.

\section{Results}

The results of the present study showed that there is an obvious weakness in the marketing of date processing-complementary industries throughout the study area, therefore, using new methods can address these shortcomings. In the present study, the TIM approach and its components make the marketing process of this strategic and important product more effective. Since marketing is one of the most important factors to increase incomes of the farmers in this region, it can be said that improving marketing leads to better condition in terms of welfare of the owners of these industries. Moreover, it can help in the globalization of these industries.

Comments of palm industry owners are given in Table 1. In order to determine their importance, the items in the components of marketing were ranked based on their corresponding factor loadings in the final structural equation model. The results of Table 1 
Table 1 Descriptive statistics for marketing in processing industries

\begin{tabular}{lllll}
\hline Item & Mean rand & SD & $\begin{array}{l}\text { Coefficient of } \\
\text { variation }\end{array}$ & Rank \\
\hline Local culture in packing & 3.70 & 1.00 & 0.270 & 1 \\
Using communication tools in marketing & 4.14 & 1.26 & 0.305 & 2 \\
impact of customer-orientation approach & 3.62 & 1.11 & 0.306 & 3 \\
Packing methods according to international standards & 3.20 & 1.00 & 0.312 & 4 \\
Modern transportation methods & 3.67 & 1.15 & 0.313 & 5 \\
Proper warehousing & 3.65 & 1.15 & 0.315 & 6 \\
Preserving quality by type of packing & 3.11 & 0.99 & 0.318 & 7 \\
International brand in date packing & 3.77 & 1.21 & 0.320 & 8 \\
Appropriate pricing in marketing & 3.53 & 1.14 & 0.322 & 9 \\
Internal branding in date marketing development & 3.57 & 1.16 & 0.324 & 10 \\
Date brand advertisement & 1.32 & 1.23 & 0.336 & 11 \\
Using advanced technology of date packing & 2.93 & 1.10 & 0.375 & 12 \\
Seller information about the brand for the customer & 3.12 & 1.21 & 0.387 & 13 \\
Date packing in terms of appearance and adequate infor- & 3.28 & 1.27 & 0.387 & 13 \\
mation in international markets & & & & 14 \\
Using skilled force in packing & 3.94 & 1.18 & 0.932 & \\
\hline
\end{tabular}

Table 2 Overall fit indicators for the conceptual model

\begin{tabular}{lll}
\hline Index & Normal limit & Observed value \\
\hline DF & Larger than zero & 261 \\
Ratio of $x^{2}$ to df & Between 2 and 5 & 3.153 \\
Goodness of fit (GFI) & 0.9 and larger & 0.941 \\
Normed Fitness Index (NFI) & 0.9 and larger & 0.925 \\
Non-Normed Fitness Index (NNFI) & 0.9 and larger & 0.950 \\
Incremental Fit Index (IFI) & 0.9 and larger & 0.963 \\
Root mean square error of approximation (RMSEA) & Below 0.05 & 0.027 \\
$p$-value & Below 0.05 & 0.124 \\
PNFI & Below 0.05 & 0.580 \\
\hline
\end{tabular}

indicate that "Local culture in packing" is ranked highest among the items of packing in processing industries and the item "using skilled force in packing" has the lowest priority.

Designing a development model for palm processing industries with emphasis on total innovation management has been demonstrated with emphasis on comprehensive management of innovation using the Structural Equation Model. Structural equation modeling was performed using the AMOS software. The model illustrates a special causal structure between a set of latent constructs. Measurement and structural models were constructed; the structural model was derived from the measurement model after items with weak loadings were trimmed. A structural equation model is composed of two components: a structural model that specifies the causal structure between the latent variables and a measurement model that represents the relationships between latent variables and observed variables. Figure 1 shows the structural model of this research.

Using general value indicators, the question can be answered that regardless of the specific values reported for the parameters, is the model generally supported by the 
collected experimental data or not? If the answer is yes, the model is acceptable. Otherwise, efforts should be made to correct it. To interpret the values in Table 2, we must say: the second root index of the average of the remaining squares, or RMSEA, indicates whether the developed model can be considered acceptable. This index is known as one of the bad indicators of value. Its value varies between zero and one, and the smaller the value obtained, the more acceptable the developed model is considered. For the developed factor model, it indicates that the model is acceptable. Comparative indicators have also been developed to evaluate the acceptability of the model based on its comparison with the independence model. These indicators take values between zero and one, and values above 0.90 have been interpreted as acceptable values in most sources. In the table (5), the Luke Toker Value Index (TLI), which is the same as (NNFI), is 0.950 , and the Comparative Value Index (IFI) is 0.960 , and their values are more than 0.90 . Therefore, based on these indicators, the developed model is considered acceptable.

Structural equation model was used for testing the research hypotheses (investigating for a significant positive relationship between development of date processing industries and organizational, technological, strategic, cultural, and underlying individual variables).

Factor loadings in Fig. 2 indicate positive significant relationship between development of date processing industries variable and each of elements of strategic innovation, technology management, innovation culture, and organizational structure. Factor loadings for strategic innovation, innovation culture, technology management, and organizational structure are $0.65,0.82,0.56$ and 0.79 , respectively. According to the results of this analysis, the research hypotheses are supported. Each of the elements in the components of the model is ranked based on the factor loadings represented in the path diagram (Fig. 2). In the culture of innovation, the item "vast database of information and resources related to marketing" is ranked highest with a standardized regression weigh of 0.79. Then "the attempt of date industries for Global trade" with a factor loading of 0.60 is ranked second. In strategic innovation, the element "long-term investment in the transformation and complementary industries" with a factor loading of 0.76 is of highest rank, and "the presence of palm growers and owners of palm industries at the university's dissertations" with a regression weight of 0.69 is ranked second. According to these results, the field of investment in machinery will improve the productivity and safety of workers in palm trees, which is in line with the research results of Gagliardi et al. (2014).

In technology management, "the use of new technology" with a factor loading of 0.73 is the major component and "management of technology with business strategy" with a factor loading of 0.52 is ranked after that. This finding is consistent with the results of Ali Abadi et al., Troott (2017). In organizational structure, "corporate governance with open and honest communication" with a factor loading of 0.79 is ranked highest and "financial incentives" with a factor loading of 0.72 is ranked second. In psychological characteristics, "risk" with a factor loading of 0.81 , the "internal control" with a factor loading of 0.72 , are ranked first and second, respectively, which is consistent with the results of Efrat et al. (2017). According to Table 2, of the indices of model fit ( $x^{2}$ to $\mathrm{df}=3.153$, $\mathrm{GFI}=0.941, \mathrm{RMSEA}=0.027, p$-value $=0.124)$, all reasonably well indicate the model fits the research data. These fit indices are in the acceptable criteria and justify the credibility of the structural equation model. 


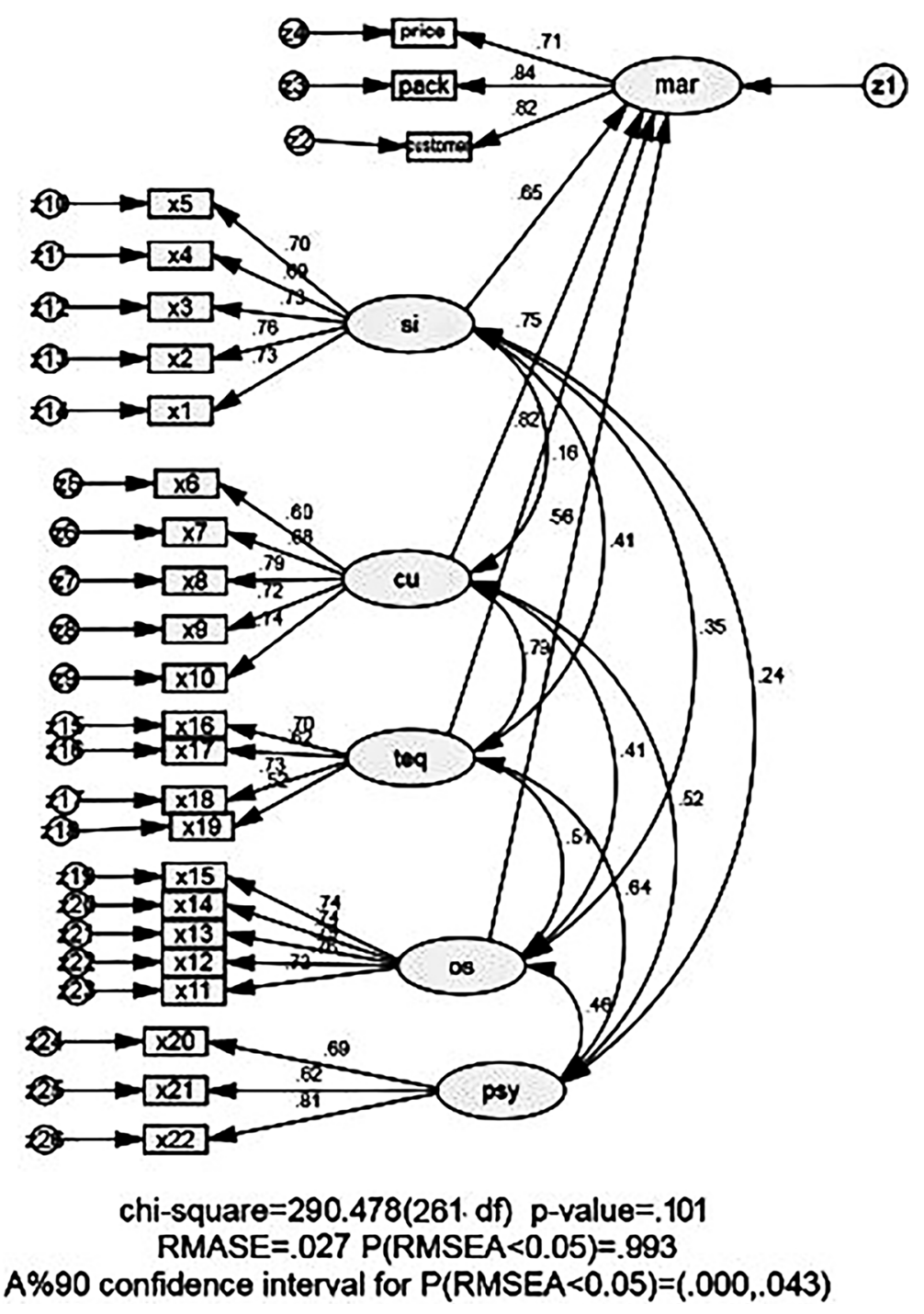

Fig. 2 Path diagram of the research model

\section{Conclusions}

The date processing industry has several potential benefits. These industries must consider the upcoming challenges to be successful in the marketing development of processing industries. This study shows that the marketing complexities of the date processing industry can be significantly influenced by organizational structure, technology management, strategic innovation, innovation culture and individual tendencies. However, the results showed that there is not a positive, significant relationship between individual tendencies and marketing of date processing industries.

Challenges related to the development of date processing industries should be categorized. This research provides these effective factors by examining theoretical sources along with a conceptual model. Local culture in packaging is the most important factor in the development of processing industries. 
The application of communicational tools for marketing and introducing a product is the second priority, i.e., communicational tools such as media environmental advertisements and personal contacts can be effective for marketing the date processing industry.

In the structural model of TIM in the development of date technology industries, the first priority of "extensive database of marketing-based information and resources" shows that the owners of industry believe that governments should make long-term investments on the advanced packaging machines". Technology management with respect to business and globalization strategy is one of the priorities of the owners of this industry, in which creating social media so that farmers and industry owners easily have an access to this information. Furthermore, extensive cooperation between "the presence of industry owners, farmers and university professors who can be experts in this field" can be significantly effective in marketing development.

Managers of date processing industries must improve the organizational structure to promote the date processing industries, the most important factor for which is an open-minded and honest management that brings new ideas leading to increased globalization and development of processing industries. Globalization increases competitiveness. The use of new technology is one of the important factors in the development of processing industries, but it should be in line with localization leading to higher rate of employment. Marketing skills, including advertising is one of the most important variables in the development of processing industries are very important in the development of this industry. To achieve international markets and develop these industries, all aspects of innovation should be utilized, in this respect. Due to the high capabilities and capacities of the province, the level of innovation and creativity in the agro-processing industries of date production needs to be reviewed so that appropriate policies will be applied to eliminate restrictions, also, utilize existing rural and agricultural capabilities.

Abbreviation

TIM: Total innovation management.

Acknowledgements

Not applicable.

Authors' contributions

All authors have equally contributed to this study from proposal development to manuscript writing stages. All authors read and approved the final manuscript.

Funding

No funding has been received by the authors for this research.

Availability of data and materials

The datasets generated during and/or analyzed during the current study are available from the corresponding author on reasonable request.

\section{Declarations}

Competing interests

The authors declare that they have no competing interests.

Author details

${ }^{1}$ Department of Economics, Agricultural Extension and Education, Science and Research Branch, Islamic Azad University, Tehran, Iran. ${ }^{2}$ Agricultural Development Department, Islamic Azad University, Karaj Branch, Tehran, Iran. ${ }^{3}$ Agricultural Development and Education, Science and Research Branch, Department of Economics, Agricultural Extension 
and Education, Science and Research Branch, Islamic Azad University, Tehran, Iran. ${ }^{4}$ Present Address: Department of Economics, Agricultural Extension and Education, Science and Research Branch, Islamic Azad University, Tehran, Iran.

Received: 24 February 2021 Accepted: 15 September 2021

Published online: 19 November 2021

\section{References}

Abbasi, A., \& Mohammadian, M. (2007). Survey of Relation between Users'view towards Websites and Internet Advertising Effectiveness. Journal Management System, 7, 99-119.

Adriadi Ghiffari, R. (2016). Development of eucalyptus oil agro-industries in Kabupaten Buru. Procedia - Social and Behavioral Sciences, 227, 815-823.

Afrasyaby, N., (2010), Packing, Deputy of Exhibitions, Managing Marketing Issues

Ali Abadi, M., Alam al-Hoda, V., Jirfeni, N., \& Fazl, SH. (2009), Smart packaging in the food industry, National Symposium on Chemical Engineering of Islamshahr, Young Researchers Club

Behbahani, L. (2017). Use of date waste in date conversion and complementary industries. Publisher.

Braun, C.-F. (1997). The innovation war. Upper Saddle River, NJ: Prentice Hall.

Chaboud, G., \& Daviron, B. (2017). Food losses and waste: Navigating the inconsistencies. Global Food Security., 12, 1-7.

Christensen, C. M. (1997). The innovator's dilemma. Boston, MA: Harvard Business School Press.

Clare Ahearn, M., Liang, K., \& Goetz, S. (2018). Farm business financial performance in local foods value chains. European Journal of Innovation Management. https://doi.org/10.1108/AFR-08-2017-0071

Davis, L. E., \& North, D. C. (1970). Institutional change and American economic growth: A first step towards a theory of institutional innovation. Journal of Economic History, 30(1), 131-149.

Dey, A., \& Gupta Singh, K. G. (2018). Innovation, investment and enterprise: Climate resilient entrepreneurial pathways for overcoming poverty. Agricultural Systems. https://doi.org/10.1016/j.agsy.2018.07.013

Dolgui, A., \& Proth, M. (2010). Pricing strategies and models, journal homepage: www.elsevier.com/locate/arcontrol. Annual Reviews in Control, 34, 101-110.

Efrat, K., Gilboa, S. H., \& Yonatany, M. (2017). When marketing and innovation interact: The case of born-global firms. International Business Review, 26(2), 380-390.

Eskandarpour, B., Kavoshi Klashi, M., Rafiee, M., \& Khaligh Khiavi, P. (2014). Law of one price and integration in date world markets. Journal of Agricultural Economics Research, 6(3), 159-174.

Food Industry Strategic Plan (2016)

Gagliardi, D., Niglia, F., Battistella, C. (2014). Evaluation and design of innovation policies in the agro-food: An application of multilevel self-regulating agents. Technological Forecasting \& Social Change, 85, 40-57.

Ganzer, P., Chais, C., \& Munhoz-Olea, P. (2018). Product, process, marketing and organizational innovation in industries of the flat knitting sector. RAl Revista De Administração e Inovação, 14, 321-332.

Hamilton, N. (2005). Farmers Market Policy An Inventory of Federal, State, and Local Examples, Prepared for Project for Public Spaces, with funding from the W. K. Kellogg Foundation.

HLPE., (2014). Food losses and waste in the context of sustainable food systems. A report by the High Level Panel of Experts on Food Security and Nutrition of the Committee on World Food Security, Rome.www.fao.org/3/a-i3901e. pdf. Accessed 02/02/2016

Imani Jajarmi, H., (2009). Assessing and analyzing the entrepreneurial characteristics of Dehyaran (Case study: Dehyaran villages of Miandoab city) Master's thesis with the financial support of the municipality and Dehyaran organization.

Janszen, F. (2000). The age of innovation: Making business creativity a competence. Not a coincidence. Prentice Hall.

Karami, A., Faryabi, M., \& Ahmadvand, M. (2019). Analysis of the establishment of conversion and complementary industries in the agricultural sector Case study of the central part of Jiroft. Quarterly Journal of Space Economics and Rural Development, 8(2), 223-238.

Klerkx, L., \& Leeuwis, C. (2008). Balancing multiple interests: Embedding innovation intermediation in the agricultural knowledge infrastructure. Technovation, 28, 364-378.

Lacy, W. (2001). Generation and commercialization of knowledge: trends, implications and models for public and private agricultural research and education. In: Wolf, S.A., Zilbermann.

Leeuwis, C., \&Van den Ban, A. (2004). Communication for Rural Innovation: Rethinking Agricultural Extension. Blackwell Science.

Levidow, L., Sogaard, V., \& Carr, S. (2002). Agricultural public-sector research establishments in Western Europe: Research priorities in conflict. Science and Public Policy, 29(4), 287-295.

McLeod Rivera, W., \& Kalim Qamar, M. (2003). Agricultural extension, rural development and the food security challenge. FAO.

OECD. (2005). Oslo manual: Guidelines for collecting and interpreting innovation data (3rd ed.). OECD Publishing.

Olamade, O. (2014). Impact of Total Innovation Management on SupplyChain in Nigeria's Automobile Industry. Journal of Entrepreneurship and Business Innovation., 1, 1.

Omani, A., \& Salmanzadeh, S. (2015). Identifying the effective factors on innovation management in conversion and complementary industries of livestock products in rural areas of Khuzestan province. Village and Development, 16(4), $121-141$.

Poorramezan, A., \& Akbari, Z. (2014). Effects of the Agricultural Processing Industries on the Rural Economy Case Study: Central District of Rasht. Quarterly Journal of Rural Space and Rural Development, 4, 145-164.

S. H. Qami, Mohammadzadeh Nesarabadi, (2011), Rural Industries, Payame Noor University Press Statistics of the Ministry of Jihad Agriculture. (2017) Results of Garden Products Sampling Survey. note book

Rapp, A., Trainor, K., \& Agnihotri, R. (2010). Performance implications of customer-linking capabilities: Examining the complementary role of customer orientation and CRM technology. Journal of Business Reseaech. https://doi.org/10. 1016/j.jbusres.2009.11.002 
Rivera, W.M. (2000). The Changing Nature of Agricultural Information and the Conflictive Global Developments Shaping Extension.

Roussel, P. A., Saad, K. N., \& Erickson, T. J. (1991). Third generation R\&D: Managing the link to corporate strategy. Harvard Business School Press.

Shafei, R., Naziripour, M. (2013). The Effect of Marketing Capabilities on the Process of Establishing Marketing Management in Small and Medium Enterprises (A Study in Industries). Kurdistan Province. First National Marketing Conference: Opportunities and Challenges, Mashhad, pp. 13-1

Statistics of the Ministry of Agriculture. (2017) Results of Garden Products Sampling Survey. note book.

Tilman, D., \& Clark, A. (2015). Food, agriculture \& the environment: Can we feed the world \& save the earth? The MIT Press Journals. https://doi.org/10.1162/DAED_a_00350

Troott, p, Simms, CH. (2017). An examination of product innovation in low- and medium-technology industries: Cases from the UK packaged food sector

Truong, Y., Klink, R., Simmons, G., Grinstein, A., \& Palmer, A. (2017). Branding strategies for high-technology products: The effects of consumer and product innovativeness. Journal of Product \& Brand Management. https://doi.org/10.1016/j. jbusres.2016.07.003

Tsai, C. H., \& Wang, Y. (2017). Experiential value in branding food tourism. Journal of Destination Marketing \& Management., 6, 56-65.

Xu, Q., Chen, J., Xie, Z., Liu, J., Zheng, G., \& Wang, Y. (2007). Total Innovation Management: a novel paradigm of innovation management in the 21 st century. Journal of Technology Transfer, 32, 9-25. https://doi.org/10.1007/ s10961-006-9007-x

Zhirong, Y., Gang, Z., Zhangshu, X., \& Gongmin, B. (2003). Total innovation management: A new emerging paradigm of innovation management, School of Management Zhejiang University, China.

\section{Publisher's Note}

Springer Nature remains neutral with regard to jurisdictional claims in published maps and institutional affiliations.

\section{Submit your manuscript to a SpringerOpen ${ }^{\odot}$ journal and benefit from:}

- Convenient online submission

- Rigorous peer review

- Open access: articles freely available online

- High visibility within the field

Retaining the copyright to your article

Submit your next manuscript at $\gg$ springeropen.com 